\title{
Pengembangan Sistem Kendali Kuantitas Air pada Tanaman Hidroponik Berbasis Internet of Things (IoT)
}

\author{
Ubaidillah Umar, Dimas Adiputra \\ Teknik Komputer \\ Fakultas Teknik Elektro \\ Institut Teknologi Telkom Surabaya \\ Jalan Ketintang No. 156 Surabaya, (+6231) 8280800 \\ ubaidillahumar@ittelkom-sby.ac.id, \\ adimas@ittelkom-sby.ac.id
}

\author{
Helmy Widyantara \\ Teknologi Informasi \\ Fakultas Teknologi Informasi dan Industri \\ Institut Teknologi Telkom Surabaya \\ Jalan Ketintang No. 156 Surabaya, (+6231) 8280800 \\ helmywid@ittelkom-sby.ac.id
}

Diterima : 17 November 2020. Disetujui : 25 November 2020. Dipublikasikan : 3 Desember 2020.

Abstract - Along with the development of urban areas that continue to develop resulting in a land that was previously used to grow various kinds of vegetabels continues to experience narrowing and even converted into building houses. The hydroponic system can be an effective method for growing vegetabels without the availability of land. However, the implementation of this system still makes it difficult for hydroponic farmers who must at all times control water needs that are running out so quickly. This factor is caused by the evaporation process and amount of water needed by kale plants to carry out the process of photosynthesis as well as growth. The purpose of this research is to design a hydroponic system for cultivating water spinach using Water Level Control (WLC) to describe the distribution of air supply for hydroponics with air levels controlled by the system. This control system uses the Arduino as a mini computer to read the system, the HC-SR04 Ultrasonic sensor as a water level reader, 2 water pumps to fill and remove water. The results show that the plants can grow well in a hydroponic system with a controlled air level $25 \mathrm{~cm}$ from the surface of the air reservoir.

Keywords: hydroponics, water level, ultrasonic sensor, water reservoir, distribution control.

\begin{abstract}
Abstrak-- Seiring dengan pembangunan perkotaan yang terus berkembang mengakibatkan lahan-lahan yang sebelumnya digunakan untuk menanam berbagai macam sayuran terus mengalami penyempitan dan bahkan beralih fungsi menjadi bangunan rumah. Sistem Hidroponik dapat menjadi salah satu metode yang efektif untuk menanam sayuran tanpa ketersediaan lahan tanah. Namun, dalam pelaksanaanya sistem ini masih menyulitkan para petani hidroponik yang setiap saat harus mengontrol kebutuhan air yang begitu cepat habis. Faktor ini disebabkan oleh adanya proses penguapan, sekaligus banyaknya kebutuhan air yang diperlukan tumbuhan kangkung untuk melakukan proses fotosintesis sekaligus pertumbuhan. Tujuan dari penelitian ini adalah merancang sistem hidroponik untuk budidaya tanaman kangkung, menggunakan Water Level Control (WLC) untuk menggambarkan distribusi penyediaan sumber air bagi hidroponik dengan level air yang terkontrol oleh sistem. Sistem kontrol ini menggunakan Arduino sebagai komputer mini untuk mengatur kerja sistem, sensor Ultrasonik HC-SR04 sebagai pembaca tingkat air, 2 pompa air untuk mengisi dan mengeluarkan kelebihan air. Hasilnya menunjukkan tanaman kangkung dapat tumbuh dengan baik pada sistem hidroponik dengan level air terkontrol $25 \mathrm{~cm}$ dari permukaan wadah penampungan air.
\end{abstract}

Kata kunci: hidroponik, level air, sensor ultrasonik, wadah penampung air, distribution control.

\section{PENDAHULUAN}

Pengembangan industri di daerah perkotaan memicu berbagai permasalahan. Salah satunya adalah peralihan fungsi dari lahan pertanian menjadi lahan pembangunan rumah dan bangunan-bangunan penting
[1], [2]. Peralihan ini menyebabkan berkurangnya lahan bagi petani konvensional untuk bercocok tanam, sehingga produksi bidang pangan menjadi berkurang. Seperti yang ditulis oleh Badan Pusat Statistik dan Direktorat Jenderal Hortikultura bahwa pada produksi $\mathrm{kol} / \mathrm{kubis}$ di Indonesia mengalami penurunan $27,22 \%$, 
sayur bayam mengalami penurunan $2,44 \%$, dan kentang mengalami penurunan $9,16 \%$ di tahun 2018 [3], [4]. Hal ini membuktikan bahwa produksi pangan dalam hal ini adalah sayuran mengalami penurunan dari tahun 2014 hingga 2018.

Dalam menangani permasalahan di atas, masyarakat saat ini beralih menggunakan teknik hidroponik. Hidroponik berasal dari kata hydro yang berarti air dan ponos yang berarti kerja. Jadi, hidroponik dapat berarti teknik pengerjaan bercocok tanaman dengan menekankan pada pemenuhan kebutuhan nutrisi bagi tanaman. Sistem pertanian menggunakan hidroponik dapat menjadi solusi untuk mengatasi keterbatasan lahan secara efektif dan efisien [5[, [6]. Namun, proses pemeliharaan tanaman menggunakan teknik ini masih di rasa menyulitkan para petani [7]-[9]. Mereka setiap saat masih harus memantau ketersediaan air, nutrisi dalam tanaman tetap stabil setiap waktu [10]-[12]. Sehingga, hal ini membuat kebanyakan para petani kewalahan dalam mengatur waktu untuk proses penanaman lainnya setiap hari. Apalagi, proses evaporasi (penguapan) yang terjadi pada air di dalam tanaman berkurang begitu cepat, akibat dari adanya terik sinar matahari [13]-[15].

Berangkat dari permasalahan tersebut, penelitian ini memberikan inovasi pengembangan teknologi dalam hidroponik menggunakan sensor level air berbasis Arduino Uno sebagai controlling dalam pemeliharaan tanaman [16]-[18]. Mikrocontroller tersebut dapat membaca apabila level air dan nutrisi yang diperlukan kurang, maupun cukup dalam sebuah medium penanaman [19], [20]. Sehingga, para petani tidak perlu khawatir apabila dalam proses penanaman ini dilakukan dengan jarak jauh, atau pengecekan yang tidak selalu berkala, sebab kebutuhan yang diperlukan telah terkontrol oleh sensor pendeteksi volume air tersebut.

\section{METODE PENELITIAN}

Untuk pemantauan dan kontrol sistem level air digunakan satu paket media tanam sayuran berbasis hidroponik yang terdiri dari pompa aquarium 1800 , ember nutrisi 20 liter, net pot hidrot (40 buah) sebagai media tanam hidroponik. Kemudian untuk sensor level air, komunikasi dan sistem kontrol menggunakan Arduino sebagai komputer mini untuk mengatur kerja sistem, sensor Ultrasonik HC-SR04 sebagai pembaca tingkat air, 2 pompa air untuk mengisi dan mengeluarkan kelebihan air.

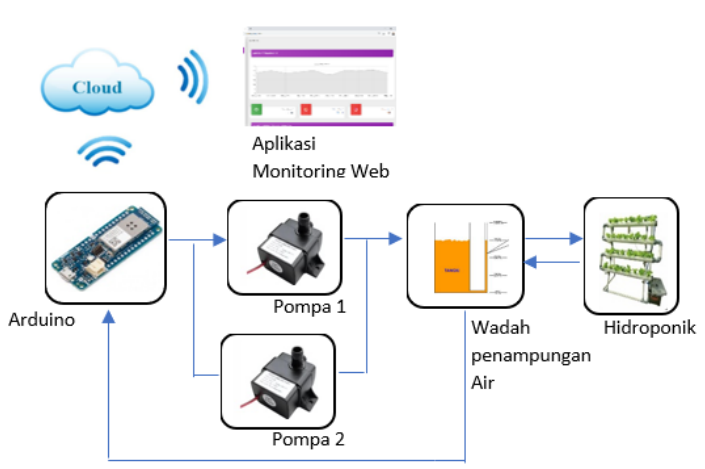

Gambar 1. Rancangan Sistem

Untuk kontrol level air, diusulkan rancangan sistem seperti ditunjukkan pada Gambar 1. Penelitian ini menggunakan Arduino sebagai komputer mini untuk mengatur volume air melalui 2 pompa air dengan cara mengisi dan mengeluarkan kelebihan air berdasarkan hasil bacaan sensor Ultrasonik HC-SR04.

\section{A. Water Level Control System (WLCS)}

Water level control system terdiri pompa aquarium 1800, bak buah nutrisi 26 liter, dan net pot hidroponik sebagai media tanam sayuran kangkung. Kemudian untuk sensor level air, komunikasi dan sistem kontrol kami menggunakan Arduino, sensor Ultrasonik dan 2 buah pompa air. Pada sistem Hidroponik memiliki data sensor level air yang kemudian dikomunikasikan ke sistem kontrol melalui Layer Communication System.

Ketinggian level air di dalam wadah penampungan air hidroponik dihitung menggunakan rumus (1),

$$
t a=t b-t s
$$

dengan $t a$ adalah tinggi air, $t b$ adalah tinggi bak keseluruhan, dan $t s$ adalah jarak permukaan air dengan sensor di bibir bak. Karena area penampang bak tidak berubah, maka untuk mempertahankan volume air cukup dengan memperhatikan tinggi air saja. Disini ta ditentukan pada ketinggian $25 \mathrm{~cm}$ dari dasar wadah penampungan air seperti ditunjukkan pada Gambar 2.

Untuk menjaga ketinggian air sebesar $25 \mathrm{~cm}$ dengan cara kendali 2 pompa untuk menambah dan mengurangi air menggunakan metode two positions control di mana pompa 1 sistemnya ditunjukkan pada Gambar 3. 


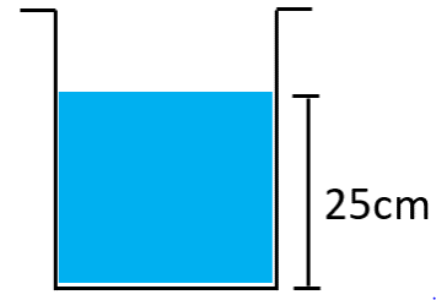

Gambar 2. Ketinggian Air yang Diharapkan

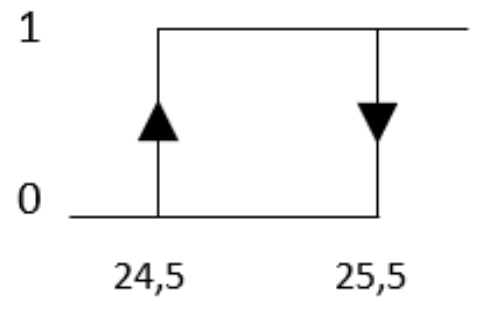

Gambar 3. Cara Kendali Pompa 1

Posisi 1 merupakan posisi dimana pompa 1 menyala sedangkan posisi 0 merupakan kondisi dimana posisi pompa mati sehingga ketika ketinggian air kurang dari $24,5 \mathrm{~cm}$ maka pompa menyala sampai keinggian air $24,5 \mathrm{~cm}$, maka diperoleh persamaan (2).

$$
\text { Signal }=1: \mathrm{t} \geq 24,5 ; 0: \mathrm{t} \leq 25,5
$$

Sedangkan untuk menjaga agar ketinggian air di dalam bak penampungan air hidroponik tidak lebih dari $25 \mathrm{~cm}$ dari dasar tempat pena1mpungan air kami menggunakan metode two position seperti yang ditunjukkan pada Gambar 4.

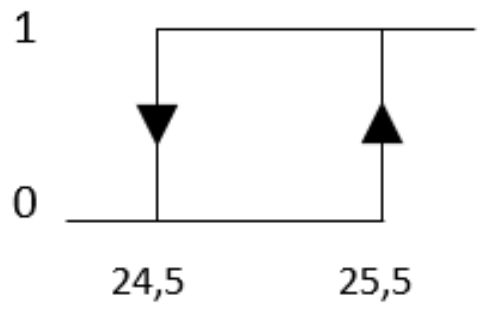

Gambar 4. Cara Kendali Pompa 2

Pompa 2 akan menyala untuk mengeluarkan kelebihan air di dalam bak penampungan air hidroponik ketika air lebih dari $25,5 \mathrm{~cm}$ dan pompa akan mati ketika ketinggian air dibawah $24,5 \mathrm{~cm}$ dengan menggunakan persamaan (3).

$$
\text { Signal }=1: \mathrm{t} \geq 25,5 ; 0: \mathrm{t} \leq 24,5
$$

dengan metode ini kondisi air akan dikendalikan berada di angka $25 \mathrm{~cm}$ dari dasar bak penampungan air dengan mengisi jika volume air kurang dari $25 \mathrm{~cm}$ oleh pompa 1 dan akan mengurangi jika pengisian air oleh pompa 2 ketika kondisi air di dalam penampungan air lebih dari $25,5 \mathrm{~cm}$ dari dasar bak penampuangan.

\section{B. Communication System (CS)}

Bagian sistem ini digunakan untuk mentransmisikan sinyal data dari sensor level air melalui sensor Ultrasonik ke sistem kontrol berbasis Arduino yang kemudian data akan ditampilkan secara realtime ke user melalui sistem monitoring berbasis web.

Gambar 5 merupakan rangkaian yang digunakan dalam mentransmisikan data sensor berupa data level air di dalam bak penampungan air Hidroponik dan juga status on/off pompa utama, pompa 1 dan pompa 2 ke sistem monitoring web melalui sinyal wifi. Proses transmisi dilakukan terus menerus secara realtime sesuai dengan kondisi air di dalam bak penampungan air Hidroponik.

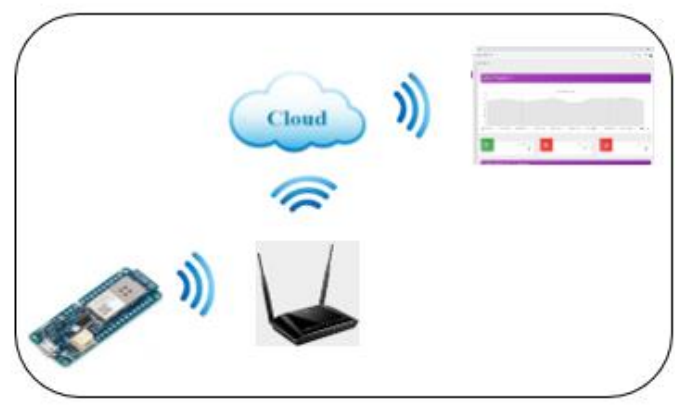

Gambar 5. Rangkaian Communicaion System (CS)

Untuk transmisi data dari sensor ke sistem monitoring web kami menggunakan akses internet modem 4G LTE dengan kecepatan downlink hingga 150 Mbps dan uplink hingga 51 Mbps. Transmisi dari sensor ke sistem monitoring web ini dilakukan secara realtime dengan menampilkan data baik berupa grafik maupun tabel di layer monitoring system.

\section{Layer Monitoring System}

Informasi yang diperoleh dari Communication System ditampilkan ke user berbasis web dengan menggunakan pemrograman PHP. Informasi yang ditampilkan yaitu grafik perubahan level air hidroponik dari waktu ke waktu kemudian terdapat juga informasi tekait status pompa utama, pompa 1 dan pompa 2 yang di-update setiap waktu. Informasi akan ditampikan secara realtime dalam bentuk grafik maupun tabel terkait kondisi level air dari waktu ke 
waktu untuk memudahkan user dalam menyimpulkan informasi yang diperoleh.

\section{HASIL DAN PEMBAHASAN}

Penelitian sistem kendali kuantitas air pada tanaman Hidroponik ini melalui 2 fase pengujian yaitu fase pengujian dimana sistem hidroponik dalam mengendalikan volume air di dalam bak penampungan air dilakukan secara manual dan fase dimana pengendalian level air dikendalikan oleh sistem IoT.

Sistem kendali yang dilakukan secara manual dilakukan dengan cara mengukur menggunakan penggaris besi untuk melihat level air yang kemudian dicatat setiap harinya sedangkan pengujian kendali level air yang dilakukan secara otomatis menggunakan sistem IoT dengan hasil data pengukuran ditampilkan ke petani dalam bentuk grafik dan tabel melalui aplikasi Monitoring berbasis Website secara realtime.

\section{A. Pengukuran Kondisi Level Air Tanpa Sistem Pengendali Level Air}

Pada tahap ini dilakukan pengambilan data yang dilakukan secara manual dengan cara mengukur menggunakan penggaris besi setiap harinya untuk memantau kondisi level air seperti yang ditunjukkan pada Gambar 6. Agar kondisi air di dalam bak penampungan air hidroponik tetap terjaga, dilakukan pengisian secara manual sampai batas level air yang diinginkan ketika air mulai berkurang.

\section{B. Kondisi Level Air Setelah Implementasi Sistem}

Pada tahap dilakukan implementasi sistem kendali kondisi air di dalam bak penampungan air berbasis $I o T$ pada tanaman Hidroponik yang salah satu tujuannya untuk mengetahui level air di dalam Bak Penampungan air setiap harinya setiap jam 7 Pagi.

Dalam melakukan pengendalian Level air berbasis $I o T$, pengisian dan pengurangan kelebihan air dilakukan secara otomatis dan secara realtime yang kemudian hasil pengembilan data dapat dimonitor oleh petani melalui aplikasi berbasis Web. Gambar 7 merupakan rangkaian perangkat sensor kendali level air secara keseluruhan.

Rangkaian ini terdiri dari Arduino sebagai komputer mini untuk mengatur kerja sistem, sensor Ultrasonik HC-SR04 sebagai pembaca tingkat level air di dalam Bak Penampungan air Hidroponik dan juga terdapat 2 pompa air yang digunakan untuk mengisi dan mengeluarkan kelebihan air Ketika pengisian oleh pompa 1 berlebih sehingga kondisi air akan senantiasa stabil di level yang ditentukan yaitu di angka $25 \mathrm{~cm}$ dari dasar bak penampungan air hidroponik.

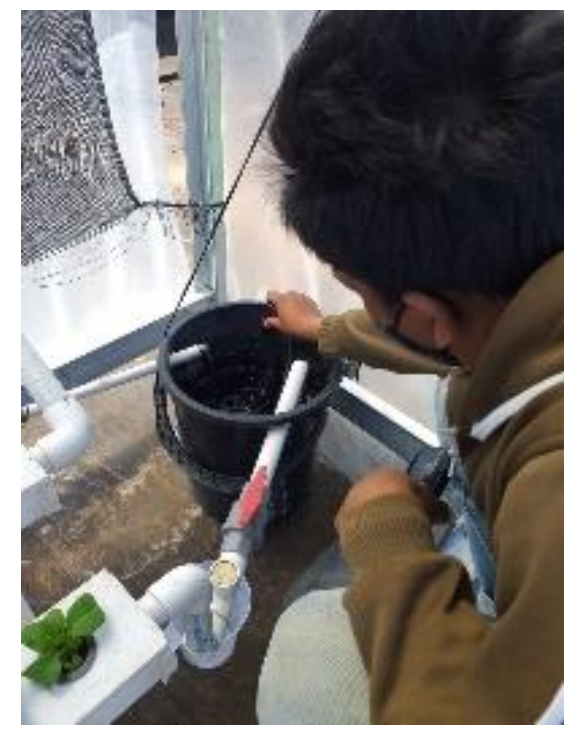

Gambar 6. Pengukuran Secara Manual

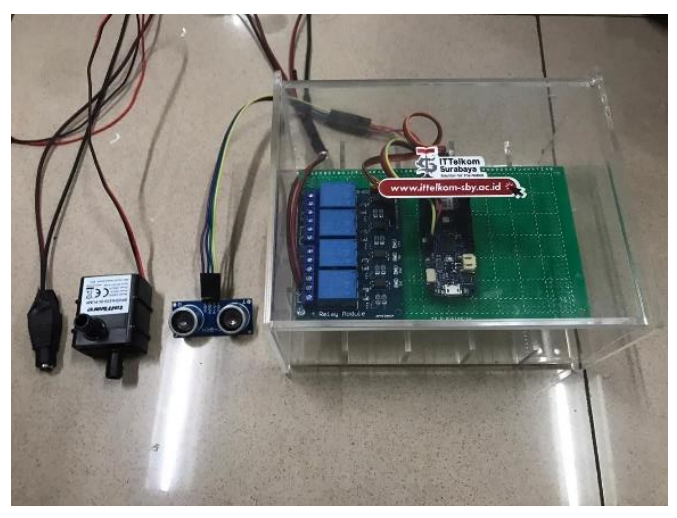

Gambar 7. Rangkaian Sensor

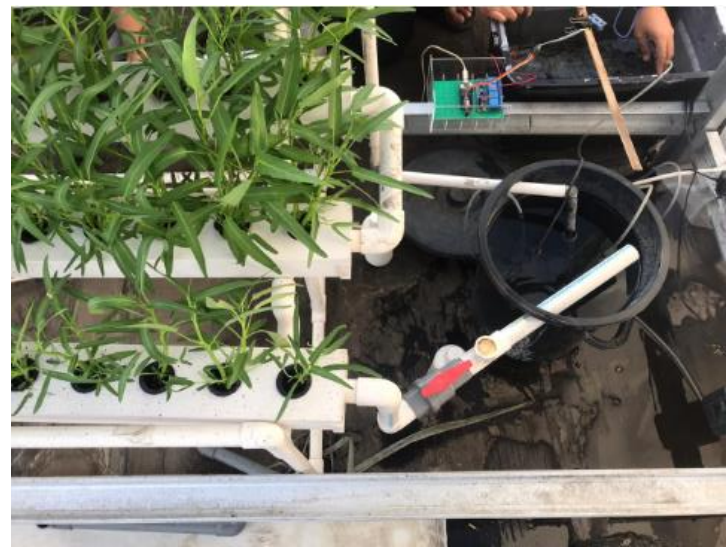

Gambar 8. Sistem Kendali yang Sudah Diimplementasikan 
Gambar 8 merupakan hasil implementasi rangkaian sistem IoT pada tanaman hidroponik. Pada perangkat tanaman hidroponik dilengkapi dengan tempat bak penampungan air dimana bak penampungan air ini dilakukan pengukuran dan kendali yang dilakukan baik secara manual maupun dilakukan secara otomatis menggunakan sistem kendali berbasis $I o T$.

\section{Pengujian Sistem}

Pengujian sistem pengendali level air dilakukan dengan cara membandingkan hasil pengendalian level air yang dilakukan secara manual dengan hasil pengambilan level air secara otomatis dengan menggunakan pengendalian air berbasis IoT. Gambar 7 merupakan data hasil pengukuran yang dilakukan secara manual selama 20 hari.

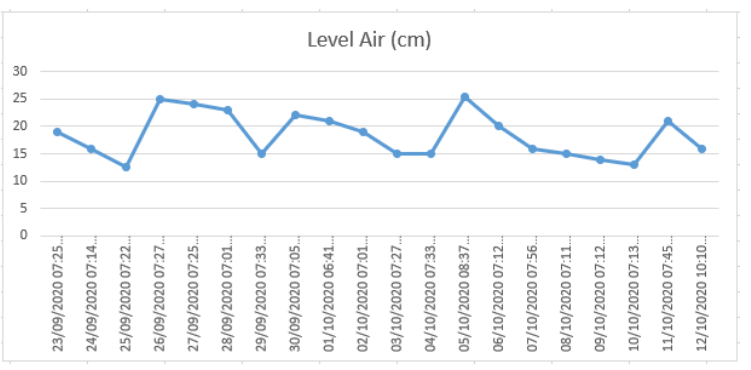

Gambar 9. Hasil Pengukuran Secara Manual

Pengambilan data dilakukan setiap hari pada pagi hari sekitar jam 7 Pagi dengan menggunakan penggaris besi. Gambar 9 merupakan gambar hasil pengambilan data dari sistem kendali level air berbasis IoT terkait kondisi level air di bak penampungan air hidroponik yang dikirim secara realtime ke sistem monitoring Web melalui Communication System (CS) setiap jam 7 Pagi.

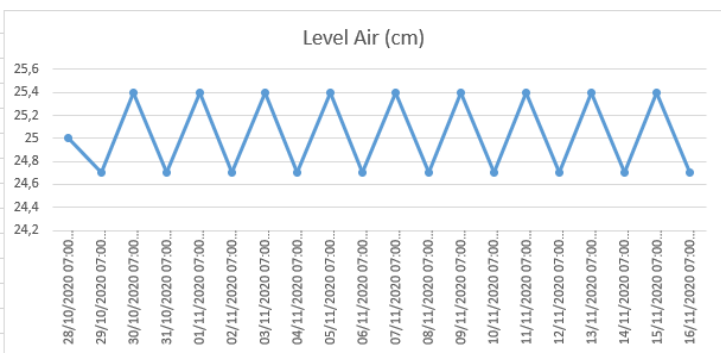

Gambar 10. Sistem Kendali yang Sudah Berhasil Dibuat dan Diimplementasikan

Kemudian Tabel I merupakan hasil pengambilan data yang dilakukan secara manual di mana berdasarkan hasil pengambilan data, ditampilkan data level air setiap pagi selama 20 hari pengukuran terlihat pada tanggal 26 September 2020 pengisian air dilakukan ketika kondisi level air di angka 12,4 cm dari dasar bak penampungan air, kemudian pada tanggal 30 september 2020 dilakukan pengisian air ketika kondisi air di angka $15 \mathrm{~cm}$, kemudian dilakukan pengisian ulang lagi pada tanggal 5 dan 11 November ketika kondisi air di angka $15 \mathrm{~cm}$ dan $13 \mathrm{~cm}$.

TABEL I. DATA LEVEL AIR DENGAN SISTEM MANUAL

\begin{tabular}{lll}
\hline No & Tanggal / Jam & Level Air $(\mathbf{c m})$ \\
\hline 1 & $23 / 09 / 202007: 25$ & 19 \\
2 & $24 / 09 / 202007: 14$ & 16 \\
3 & $25 / 09 / 202007: 22$ & 12,5 \\
$\mathbf{4}$ & $\mathbf{2 6 / 0 9 / 2 0 2 0 ~ 0 7 : 2 7}$ & $\mathbf{2 5}$ \\
5 & $27 / 09 / 202007: 25$ & 24 \\
6 & $28 / 09 / 202007: 01$ & 23 \\
7 & $29 / 09 / 202007: 33$ & 15 \\
$\mathbf{8}$ & $\mathbf{3 0 / 0 9 / 2 0 2 0 ~ 0 7 : 0 5}$ & $\mathbf{2 2}$ \\
9 & $01 / 10 / 202006: 41$ & 21 \\
10 & $02 / 10 / 202007: 01$ & 19 \\
11 & $03 / 10 / 202007: 27$ & 15 \\
12 & $04 / 10 / 202007: 33$ & 15 \\
$\mathbf{1 3}$ & $\mathbf{0 5 / 1 0 / 2 0 2 0 ~ 0 8 : 3 7}$ & $\mathbf{2 5 , 5}$ \\
14 & $06 / 10 / 202007: 12$ & 20 \\
15 & $07 / 10 / 202007: 56$ & 16 \\
16 & $08 / 10 / 202007: 11$ & 15 \\
17 & $09 / 10 / 202007: 12$ & 14 \\
18 & $10 / 10 / 202007: 13$ & 13 \\
$\mathbf{1 9}$ & $\mathbf{1 1 / 1 0 / 2 0 2 0 ~ 0 7 : 4 5}$ & $\mathbf{2 1}$ \\
20 & $12 / 10 / 202010: 10$ & 16 \\
\hline
\end{tabular}

Tabel II menunjukkan data hasil pengambilan data setelah sistem kendali level air berbasis $I o T$ pada bak penampungan air diimplementasikan. Berdasarkan hasil pengambilan data yang diperoleh, dapat dilihat data dari hari ke hari cenderung stabil pada angka $24,7 \mathrm{~cm}$ sampai $25,4 \mathrm{~cm}$.

TABEL II. DATA LEVEL AIR MELALUI SISTEM KENDALI IOT

\begin{tabular}{lll}
\hline No & Tanggal / Jam & Level Air $(\mathbf{c m})$ \\
\hline 1 & $28 / 10 / 202007: 00$ & 25 \\
2 & $29 / 10 / 202007: 00$ & 24,7 \\
3 & $30 / 10 / 202007: 00$ & 25,4 \\
$\mathbf{4}$ & $31 / 10 / 202007: 00$ & 24,7 \\
5 & $01 / 11 / 202007: 00$ & 25,4 \\
6 & $02 / 11 / 202007: 00$ & 24,7 \\
7 & $03 / 11 / 202007: 00$ & 25,4 \\
$\mathbf{8}$ & $04 / 11 / 202007: 00$ & 24,7 \\
9 & $05 / 11 / 202007: 00$ & 25,4 \\
10 & $06 / 11 / 202007: 00$ & 24,7
\end{tabular}




\begin{tabular}{lll}
\hline No & Tanggal / Jam & Level Air $(\mathbf{c m})$ \\
\hline 11 & $07 / 11 / 202007: 00$ & 25,4 \\
12 & $08 / 11 / 202007: 00$ & 24,7 \\
$\mathbf{1 3}$ & $09 / 11 / 202007: 00$ & 25,4 \\
14 & $10 / 11 / 202007: 00$ & 24,7 \\
15 & $11 / 11 / 202007: 00$ & 25,4 \\
16 & $12 / 11 / 202007: 00$ & 24,7 \\
17 & $13 / 11 / 202007: 00$ & 25,4 \\
18 & $14 / 11 / 202007: 00$ & 24,7 \\
$\mathbf{1 9}$ & $15 / 11 / 202007: 00$ & 25,4 \\
20 & $16 / 11 / 202007: 00$ & 24,7 \\
\hline
\end{tabular}

Berdasarkan data ini terlihat kondisi penurunan volume air dari hari ke hari semakin tidak menentu sehingga membuat petani kesulitan untuk menjaga agar volume tetap stabil di angka $25 \mathrm{~cm}$ dari dasar bak penampungan air.

\section{Analisa Hasil Uji Coba}

Analisa dilakukan dari hasil pengambilan data yang dilakukan secara manual dan hasil pengambilan data yang dilakukan secara otomatis menggunakan sistem IoT. Berdasarkan Hasil pengujian, Ketika sistem pengendalian level air dilakukan secara manual hasil data yang diperoleh mnenunjukkan perubahan grafik yang tidak teratur dari hari kehari. Hal ini diakibatkan oleh ketidak teraturan petani dalam menambah air ketika kondisi air di dalam bak penampungan air berkurang kemudian mengurangi level air ketika pengisian air berlebih dari batas yang seharusnya.

Penambahan air akan sering dilakukan seiring dengan semakin besarnya tanaman hidroponik yang mengakibatkan air semakin berkurang dengan cepat setiap harinya. Yang mengakibatkan kondisi level di dalam bak penampungan Hidroponik cenderung tidak sama antara hari pertama dengan hari-hari berikutnya. Selain faktor semakin tumbuh tanaman, ketidak teraturan pengurangan level air di dalam bak penampungan air juga diakibatkan oleh cuaca dimana ketika cuaca panas mengakibatkan air di dalam bak penampungan air menguap dan terbuang ke udara yang mengakibatkan konsumsi air yang semakin banyak dari hari ke hari.

Perubahan level air di dalam bak air hidroponik melalui sistem kendali IoT kondisinya stabil disekitar angka $25 \mathrm{~cm}$, yaitu di sekitar angka $24,7 \mathrm{~cm}$ dan di angka $25,4 \mathrm{~cm}$ dari dasar bak penampungan air yang mengalami pengurangan dan penambahan level air secara terus menerus dari waktu ke waktu secara otomatis oleh sistem.
Angka ini sesuai dengan level air yang sudah ditentukan di dalam program untuk menjaga ketinggian air sebesar $25 \mathrm{~cm}$ dengan cara kendali 2 pompa dengan menambah dan mengurangi air menggunakan metode two positions control untuk mengendalikan kondisi level air tetap stabil di angka $25 \mathrm{~cm}$ dari wadah penampungan air Hidroponik.

Berdasarkan hasil pengambilan data secara manual dan dari hasil monitoring berbasis web di atas terlihat grafik data pada hasil pengambilan data secara manual tidak stabil hal ini disebabkan oleh beberapa faktor diantaranya dari petani yang tidak setiap hari secara mengisi air ketika terjadi pengurangan air di dalam bak penampungan air yang mengakibatkan grafik cenderung tidak stabil. Hal ini berbeda ketika diimplementasikan sistem kendali berbais IoT dimana penambahan dan pengurangan level air di dalam bak penampungan air dilakukan secara otomatis ketika terjadi pengurangan maupun penambahan dari level air yang sudah ditentukan sehingga grafik perubahan lebih stabil dan teratur.

\section{E. Aplikasi Monitoring Level Air}

Gambar 11 merupakan tampilan Aplikasi monitoring Level air secara realtime untuk melakukan pemantauan terhadap kondisi air di dalam bak penampungan air. Pada halaman aplikasi monitoring, akan menampilkan grafik dan tabel pengurangan atau penambahan air baik sebelum pompa menyala maupun ketika pompa menyala.

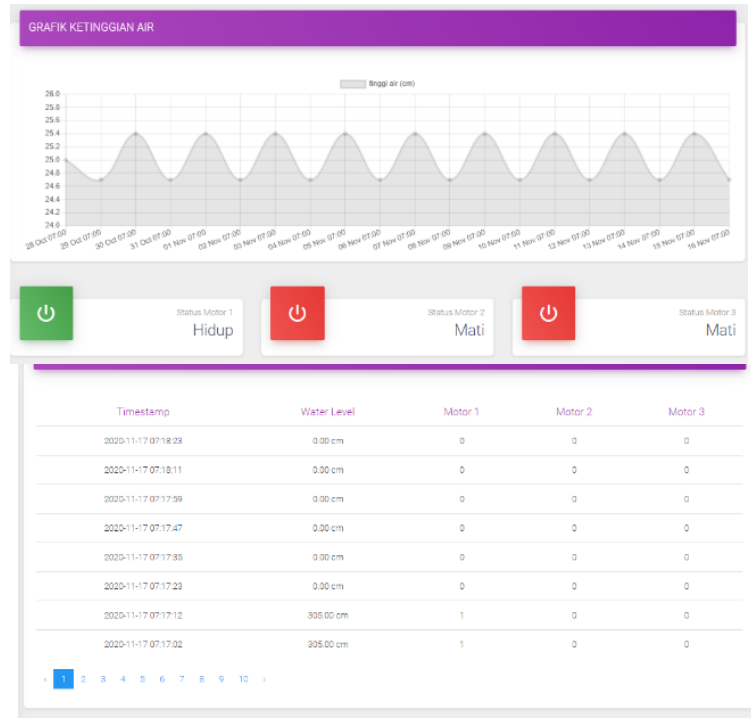

Gambar 11. Aplikasi Monitoring Level Air Berbasis Web 
Dengan aplikasi ini petani Hidroponik akan mudah dalam memantau kondisi air di dalam bak penampungan air hidroponik apakah kondisi air dalam kondisi baik yaitu volume airnya mencukupi atau kondisi air di dalam penampungan air dalam kondisi kurang untuk mengecek kondisi sistem yang sedang berjalan sehingga dengan sistem ini petani dapat memonitoring baik kondisi volume air maupun kondisi pompa dan kondisi sensor.

Berdasarkan hasil pengamatan terhadap tumbuh tanaman hidroponik, tanaman kangkung dapat tumbuh dengan baik pada sistem hidroponik dengan level air terkontrol $25 \mathrm{~cm}$ dari permukaan wadah penampungan air, di mana nutrisi dalam air yang tetap terjaga membuat tanaman tumbuh dengan baik.

\section{KESIMPULAN DAN SARAN}

Penelitian ini difokuskan pada pembuatan sistem yang dapat membantu para petani atau pemilik lahan hidroponik dalam memonitoring pemeliharan secara modern dengan IoT (Internet of Things). Hasil membuktikan bahwa pemeliharaan kuantitas air terhadap tanaman kangkung menggunakan sensor air, terintegrasi dengan mikrokontroller Arduino Uno sangat memudahkan. Air secara otomatis ditambahkan ketika air dibawah ambang batas $24,5 \mathrm{~cm}$ yang ditentukan dan akan mengeluarkan air Ketika air melebihi ketinggian sebesar $25,5 \mathrm{~cm}$ sehingga petani tidak perlu menambahkan air secara manual setiap harinya untuk memenuhi nutrisi air hidroponik.

Dari inovasi ini, diperoleh data kondisi air secara realtime dengan pantauan melalui website yang telah dibuat. Menjaga volume air berdasarkan kendali tinggi air juga membuka peluang untuk mengendalikan banyaknya nutrisi dalam air hidroponik. Efek dari rasio nutrisi dan air yg tetap terhadap pertumbuhan tanaman hidroponik juga menarik untuk diteliti kemudian.

\section{REFERENSI}

[1] Prasetyo A, Nurhasan U, Lazuardi G. Implementasi IoT pada Sistem Monitoring dan Pengendali Sirkulasi Air Tanaman Hidroponik. Jurnal Informatika Polinema. 2018; 5(1).

[2] Persoalan ini masih dihadapi petani Indonesia. 2018. [Online]. Tersedia: https://ekonomi.kompas.com/read/2018/08/02/154900926/5persoalan-ini-masih-dihadapi-petani-indonesia. [Diakses: 26 November 2020].

[3] Kementerian Pertanian Republik Indonesia, 2018. [Online]. Tersedia :https://www.pertanian.go.id/home/?show=page\&act=view\&i d=61. [Diakses: 26 November 2020]

[4] Dharma I.P.L, Tansa S, Nasibu IZ. Perancangan Alat Pengendali Pintu Air Sawah Otomatis dengan SIM800I Berbasis Mikrokontroler Arduino Uno. Jurnal Teknik. 2019.
[5] Putra.Y.H, Triyanto.D, Suhardi. Sistem Pemantauan dan Pengendalian Nutrisi, Suhu dan Tinggi Air Pada Pertanian Hidroponik Berbasis Website. Jurnal Coding, Sistem Komputer Unitan. 2018; 6(3):128-138.

[6] Ardiansah I, Putri S.H, Wibawa A.Y, Rahmah DM. Optimalisasi Ketersediaan Air Tanaman dengan Sistem Otomasi Irigasi Tetes Berbasis Arduino Uno dan Nilai Kelembaban Tanah. Ultimatics. 2018.

[7] Komaludin D. Prototype Monitoring Suhu Tanaman Hidroponik Teknologi IoT (Internet Of Things). Jurnal TrendTech. 2018.

[8] Umamaheswari, S, Preethi, A, Pravin, E, Dhanusha, R. Integrating Scheduled Hydroponic System. Proc IEEE International Conference on Advances in Computer Applications. 2016.

[9] Crisnapati, PN, Wardana, I, Aryanto, I, Hermawan, A. Hydroponic Management and Monitoring System for an IOT Based NFT Farm Using Web Technology. Proc 5th International Conference on Cyber and IT Service Management (CITSM). 2017.

[10] Rifai A, Sembiring S, Farissi A, Karo D.G.K. Perancangan Sistem Pengatur Electrical Conductivity (EC) Air Menggunakan Kendali Logika Fuzzy. Jurnal Informatik Edisi ke-16. 2020.

[11] Desnanjaya I.G.M.N, Sastrawan I.G.P, Pranata I.W.D. Sistem peringatan ketinggian air dan kendali TEMUKU (Pintu Air) untuk irigasi sawah. Jurnal RESISTOR. 2020.

[12] Ratnawati, Silma. Sistem Kendali Penyiram Tanaman Menggunakan Propeller Berbasis Internet Of Things. Jurnal Inspiration 2017; 7:2.

[13] Hari Y, Kurnia Y.A, Budijanto A. Pengembangan Sistem Kendali Cerdas dan Monitoring pada budidaya buah tomat. Seminar Nasional Sains dan Teknologi Terapan V 2017. 2017.

[14] Tajrie A.M, Sumaryo S, Ekaputri C. Sistem Kendali Penyiraman dan Pencahayaan tanaman otomatis pada smart greenhouse menggunakan logika Fuzzy. e-Proceeding of Engineering. 2017.

[15] Purwasih R, Evahelda, Agustina F, Pranoto S.Y. Pemanfaatan lahan pekarangan untuk budi daya sayungan secara hidroponik di kecamatan sungailiat, Kabupaten Bangka, Provinsi Kepulauan Bangka Belitung. Jurnal Ilmiah Pengabdian Kepada Masyarakat. 2019.

[16] Delya B, Tusi A, Lanya B, Zulkarnain I. Rancang Bangun sistem control penyiram tanaman berdasarkan Sensor Soail Moiture dengan menggunakan Arduino. Jurnal Explore It. 2019.

[17] S. Mufida Elly. Otomatisasi Irigasi Sawah Menggunakan Sensor Elktroda Level Berbasis Mikrokontroler Atmega8535. Jurnal Teknik Komputer AMIK BSI. 2017.

[18] Mardiana Y, Riska. Implementasi Dan Analisis Arduino Dalam Rancang Bangun Alat Penyiram Tanaman Otomatis Menggunakan Aplikasi Android. Jurnal Pseudocode. 2020.

[19] Pamungkas R.H.S, Riskiono S.D, Arya Y. Rancang Bangun Sistem Penyiraman Tanaman Sayuran berbasis Arduino dengan sensor kelembaban tanah, Jurnal Ilmiah Mahasiswa Kendali dan Listrik. 2020.

[20] Umar U, Rasyid.M.U.H.A, Sukaridhoto S. Distributed Database Semantic Integration of Wirelless Sensor Network to Access the Enviromental Monitoring System. International Journal of Engineering and Technology Innovation. 2018; 8(3):157- 172. 